\title{
Brief Communications \\ Heuristic Evaluation of Online COPD Respiratory Therapy and Education Video Resource Center
}

\author{
Michael Stellefson, PhD, ${ }^{1}$ Beth Chaney, PhD, MCHES, ${ }^{2}$ \\ and Don Chaney, PhD, MCHES \\ ${ }^{1}$ Department of Health Education and Behavior, University \\ of Florida, Gainesville, Florida. \\ ${ }^{2}$ Department of Health Education and Promotion, East Carolina \\ University, Greenville, North Carolina.
}

\begin{abstract}
Purpose: Because of limited accessibility to pulmonary rehabilitation programs, patients with chronic obstructive pulmonary disease (COPD) are infrequently provided with patient education resources. To help educate patients with COPD on how to live a better life with diminished breathing capacity, we developed a novel social media resource center containing COPD respiratory therapy and education videos called "COPDFlix." Methodology: A heuristic evaluation of COPDFlix was conducted as part of a larger study to determine whether the prototype was successful in adhering to formal Web site usability guidelines for older adults. A purposive sample of three experts, with expertise in Web design and health communications technology, was recruited (a) to identify usability violations and (b) to propose solutions to improve the functionality of the COPDFlix prototype. Each expert evaluated 18 heuristics in four categories of task-based criteria (i.e., interaction and navigation, information architecture, presentation design, and information design). Seventy-six subcriteria across these four categories were assessed. Quantitative ratings and qualitative comments from each expert were compiled into a single master list, noting the violated heuristic and type/location of problem(s). Results: Sixty-one usability violations were identified across the 18 heuristics. Evaluators rated the majority of heuristic subcriteria as either a "minor hindrance" $(\mathrm{n}=32)$ or "no problem" $(\mathrm{n}=132)$. Moreover, only 2 of the 18 heuristic categories were noted as "major" violations, with mean severity scores of 23. Conclusions: Mixed-methods data analysis helped the multidisciplinary research team to categorize and prioritize usability problems and solutions, leading to 26 discrete design modifications within the COPDFlix prototype.
\end{abstract}

Key words: e-health, distance learning, education, technology

\section{Background}

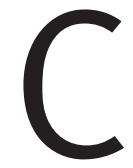

hronic obstructive pulmonary disease (COPD) is a preventable and treatable disease, caused by a mixture of chronic bronchitis and emphysema that leads to prolonged coughing and dyspnea (i.e., shortness of breath) exacer- bations that often go unreported. ${ }^{1}$ An estimated 15 million U.S. adults have been diagnosed with COPD, and it is now the third leading cause of death in the United States. ${ }^{2,3}$ Globally, it is estimated that COPD will become the third leading cause of death by $2030 .{ }^{4}$ COPD commonly affects older adults over the age of 50 years who have a history of smoking. ${ }^{5}$ Limited access to pulmonary rehabilitation programs prevents many COPD patients from obtaining patient education regarding effective self-management. ${ }^{6-8}$

To improve online patient education resources for COPD patients, who often experience cognitive and attentive impairments, ${ }^{9}$ a multidisciplinary group of researchers, clinicians, information technology specialists, and multimedia designers created "COPDFlix" (www .copdflix.com) using an adapted version of the Web site developmental model for the healthcare consumer. ${ }^{10}$ COPDFlix was designed as a low computer-literate social media resource center providing online access to evidence-based COPD patient education videos. ${ }^{11-13}$ Our Web platform used a broad and shallow navigational architecture to upload 167 brief videos into distinct COPD patient education categories. Videos were embedded using YouTube.

Prior to testing COPDFlix with patients, we assembled a small panel of usability experts to identify usability violations against a list of recognized Web design principles for older adults (i.e., "heuristics"). ${ }^{14}$ During a heuristic evaluation, experts identify system violations and assign each a severity score that is accompanied by a qualitative description of how to fix the problem. Two to five evaluators with usability expertise can detect 75\% of usability problems. ${ }^{15,16}$

\section{Materials and Methods}

Three usability experts in Web design and health communications technology were recruited as a purposive sample to conduct the heuristic evaluation. Each evaluator completed eight typical user tasks (Table 1), such as locating videos, posting comments, and contributing to online discussion threads. After completing the tasks, experts completed a survey that assessed 18 task-based heuristic criteria for evaluating Web sites for older adults. ${ }^{17-19}$ We administered 76 subcriteria items related to four main categories: (1) 20 items on interaction and navigation (i.e., the way users work with the site), (2) 18 items on information architecture (i.e., organization of links and hierarchy of content categories), (3) 20 items on presentation design (i.e., graphical interface and visual elements), and (4) 18 items on information design (i.e., preparation of communication products to achieve specified performance objectives). Experts assigned ratings of all subcriteria items on a 4-point scale (where $1=$ "no problem" or satisfies the heuristic, 2 = "minor hindrance" or possible issue that will probably not hinder the user, 3 = "serious problem" that may 


\section{ONLINE COPD RESPIRATORY THERAPY AND PATIENT EDUCATION}

\begin{tabular}{|c|c|}
\hline $\begin{array}{c}\text { TASK } \\
\text { NUMBER }\end{array}$ & DESCRIPTION OF TASK \\
\hline 2 & Review the video category labels on the left-hand side of the computer screen in blue and indicate which (if any) is unclear. \\
\hline 3 & Play the "deep breathing" video under the blue "stress management" category label. \\
\hline 5 & $\begin{array}{l}\text { Click on the "Talk to Other People with COPD" category label at the bottom of the page and post a one-sentence comment on the discussion topic } \\
\text { of your choice. }\end{array}$ \\
\hline 6 & Click on one of the videos that is "Recommended for You" and play the video. \\
\hline 7 & $\begin{array}{l}\text { Imagine you have just found this Web site online at your home or at the library. For the next } 5 \mathrm{~min} \text { or so, please explore the Web site however you } \\
\text { would like. }\end{array}$ \\
\hline
\end{tabular}

COPD, chornic obstructive pulmonary disease.

hinder the user, or $4=$ "task failure" preventing the user from going forward). Each expert was also asked to provide explanatory qualitative commentary for each subcriteria rating.

\section{DATA ANALYSIS}

Quantitative ratings and qualitative comments were compiled into a single master list, noting the violated heuristic and type/location of problem(s). Duplicate usability problems from multiple evaluators were grouped and treated as a single unit. SPSS version 22.0 software (SPSS Inc., Chicago, IL) was used to compute the mean ( \pm standard deviation [SD]) severity rating scores for all 76 subcriteria. Mean severity scores of $\geq 3$ and those with SD error bars exceeding 3 were categorized as "major" violations needing solutions. Heuristics with mean severity scores of $>2$ but $<3$ were described as "moderate" violations in need of further consideration. "Minor" violations were characterized by mean severity scores of $\leq 2$ and were addressed if experts noted the violation as likely to hinder the user from successfully utilizing COPDFlix. Qualitative data were coded using Atlas.ti version 7.0 software (ATLAS.ti Scientific Software Development $\mathrm{GmbH}$, Berlin, Germany) with a process of deductive constant comparison analysis, ${ }^{20}$ which organized potential design solutions by each of the four heuristic categories.

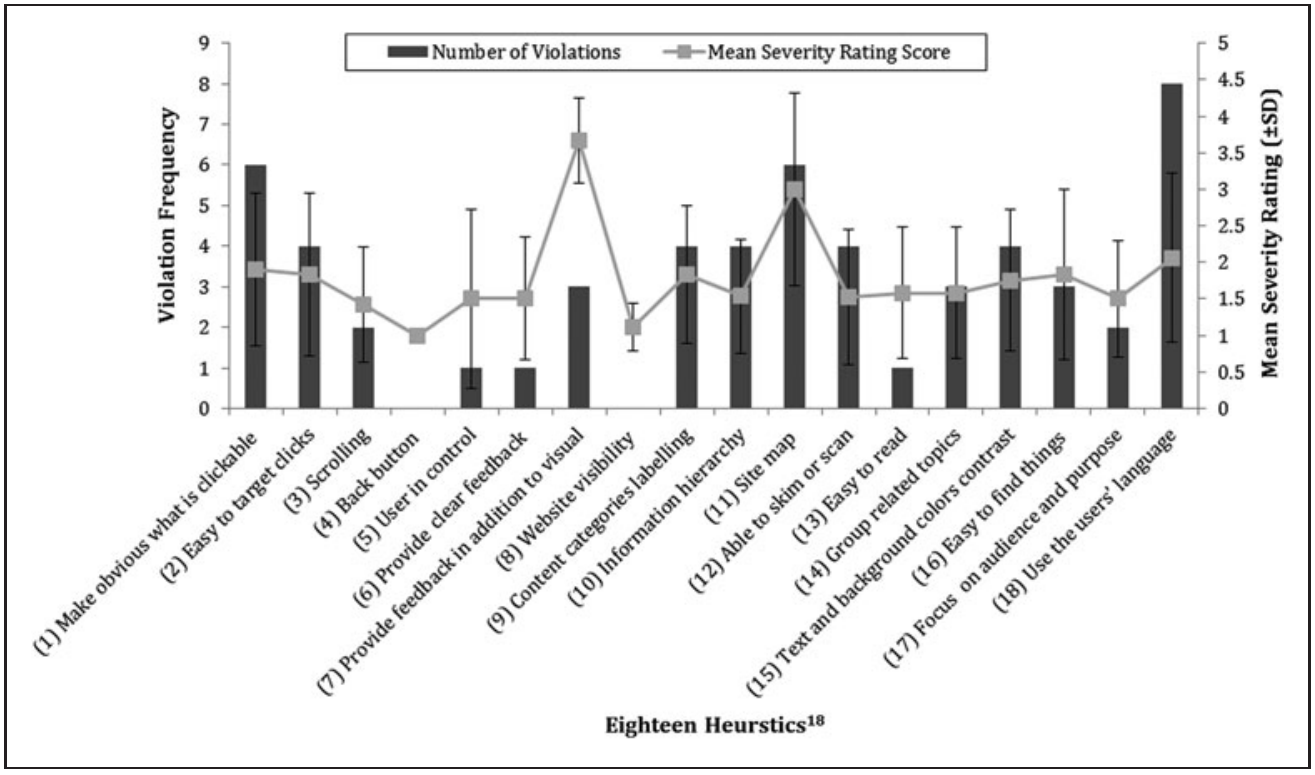

Fig. 1. Severity of usability violations $(n=61)$ by heuristic category. SD, standard deviation.

\section{Results and Discussion}

When considering data from each of the three experts on the 76 subcriteria, we found that most were rated as a "minor hindrance" $(n=32$, $14 \%)$ or "no problem" $(n=132$, $57.9 \%)$. Only 2 of the 18 heuristic categories earned mean severity scores of $\geq 3$ (i.e., "major" violations). However, evaluators did identify 61 violations across the four categorical domains (information design, $n=18$; interaction and navigation, $n=17$; information architecture, $n=14$; presentation design, $n=12$ ). The three most frequently violated heuristics were "Use the users' language; minimize jargon and technical terms" $(n=8)$, "Include a site map and link to it from every page" $(n=6)$, and "Make obvious 


\section{STELLEFSON ET AL.}

what is clickable and what is not" $(n=6)$ (Fig. 1). The heuristic for using nontechnical language was violated to a "moderate" degree (mean, 2.06; $\mathrm{SD}=1.16$ ), whereas lack of a site map was noted to be a major violation (mean, $3 ; \mathrm{SD}=1.32$ ). Although lack of a site map reached the major violation threshold, it was noted by all evaluators that a site map was not likely to improve users' navigation of COPDFlix, given that the prototype already possessed a topicdelimited Web architecture. Experts did propose modifying video category labels to be written in plain language, however (e.g., "use 'breathe' instead of 'exhale"'). The heuristic on "clickability" received a mean severity score of $<2($ mean, $1.90 ; \mathrm{SD}=1.04)$, indicating a minor violation. Although the raw number of violations on the "Provide feedback in other modes in addition to visual" heuristic was low $(n=3)$, its mean severity score was high (mean, 3.67; SD =0.58). Experts explained that adding brief text-based descriptions of video content would reduce the seriousness of this major violation. The presentation design category had the fewest violations, suggesting that visual elements were appropriate for the intended audience. Overall, evaluators rated COPDFlix as possessing mainly inconsequential violations.

Quantitative severity ratings and qualitative technical feedback from experts helped prioritize usability problems and design

\section{Table 2. Representative Qualitative Commentary from Expert Evaluators by Heuristic Category HEURISTIC CATEGORY \\ EXPERT COMMENTS}

\begin{tabular}{l|ll} 
Interaction & "The videos do not have meaningful captions. On YouTube, there's a way to add captions to videos, but this requires the user to import an
\end{tabular} and navigation accurate transcript. For a user to turn on captions, they have to click the 'CC' button on the video player, which then gives them several options, some of which aren't relevant...Manually captioning each video is a lot of work, but it might be beneficial for this audience. Another possibility would be to superimpose the captions on the video itself so that they are always on." E1 H7 S1

"For the majority of videos, I saw no captioning or alternative text. The COPD explanation animation on the Welcome page seemed to be more oriented to students or health professionals than patients-the language completely turned me off." E2 H7 S1

"While having links stay the same regardless of clicking makes for a cleaner looking site, older adults might need the visual reminders of changing link color so they know what they've visited in case they've forgotten." E1 H1 S3

"For the main links, yes, they change visibly. But for all other links on the page, like the sign-in link, recommended videos, links at the bottom, and links on the resources page, none of these things change when hovering with the mouse." E1 H1 S7

"They [category labels] show that they've been clicked while you're in that section, but when you go to another section, you can't see that you've already been to a particular section." E2 H1 S3

"The videos do not show whether they have already been viewed." E3 H1 S3

Information $\quad$ "There is no site map. Even though most people don't use a sitemap, there should still be one, and this should be displayed in that bottom navigation architecture bar." E1 H11 S1

"I don't see anything I'd identify as a site map, but I don't know how helpful that would be to older adults. Maybe something at the bottom of the page that would list all the categories and then what's available under each would help one re-locate videos that might be located under multiple categories." E2 H11 S1

"No site map is presented on the Web site, other than the menu itself." E3 H11 S1

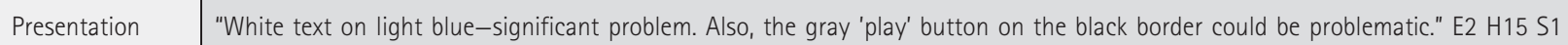

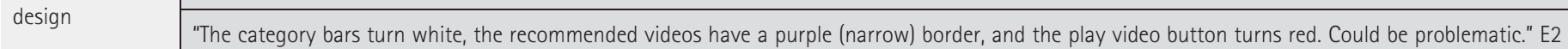
H15 S4

Information "There doesn't appear to be a definitions page or anything. I couldn't even find written text for what 'COPD' stands for. The videos themselves, though, design $\quad$ usually explain medical words or phrases in simple language." E1 H18 S3

"There is no safety information in written form. Some videos, like the Infection Treatment video, do provide appropriate safety information, but this should be supplemented with text outside the video." E1 H18 S4

"Seems like it would be helpful if the site had a glossary." E2 H18 S3

"For some low-income individuals, 'exhale' is probably not as clear as 'breathe out."' E2 H18 S5

"There's very little text, but sometimes it goes by too fast in the videos." E2 H18 S6

"The language seems pretty straightforward and simplified." E3 H18 S3

$\mathrm{COPD}$, chronic obstructive pulmonary disease; $\mathrm{E}_{1}$ evaluator; $\mathrm{H}$, heuristic number; $\mathrm{S}$, subcriteria number. 


\section{ONLINE COPD RESPIRATORY THERAPY AND PATIENT EDUCATION}

\begin{tabular}{|c|c|c|c|}
\hline $\begin{array}{l}\text { HEURISTIC } \\
\text { CATEGORY }\end{array}$ & $\begin{array}{l}\text { VIOLATED } \\
\text { HEURISTIC }\end{array}$ & $\begin{array}{l}\text { DESCRIPTION } \\
\text { OF VIOLATION(S) }\end{array}$ & $\begin{array}{c}\text { EXAMPLE OF } \\
\text { DESIGN SOLUTION(S) }\end{array}$ \\
\hline & $\begin{array}{l}\text { \#7: Provide feedback } \\
\text { in other modes in addition } \\
\text { to visual (major) }\end{array}$ & $\begin{array}{l}\text { - No meaningful captions or alternative text provided to } \\
\text { users in addition to the videos } \\
\text { - Some videos seemed more oriented to medical students } \\
\text { or health professionals rather than patients, with non- } \\
\text { plain language inappropriate for a patient. }\end{array}$ & $\begin{array}{l}\text { Design solution: Developing short two-sentence } \\
\text { captions that described content in each video and } \\
\text { inserted them underneath the comment boxes beneath } \\
\text { each video. Also developing transcripts of video content } \\
\text { to import into YouTube for captioning the video } \\
\text { in English }\end{array}$ \\
\hline \multirow[t]{2}{*}{$\begin{array}{l}\text { Interaction and } \\
\text { navigation }\end{array}$} & $\begin{array}{l}\# 9 \text { : Clearly label content } \\
\text { categories; assist recognition } \\
\text { and retrieval rather than } \\
\text { recall (minor) }\end{array}$ & $\begin{array}{l}\text { - Order of videos on some of the pages could use some } \\
\text { more structure to minimize scrolling. } \\
\text { - Not all category labels would be easily recognizable. }\end{array}$ & $\begin{array}{l}\text { Design solution: Combine common videos on medication } \\
\text { use pages and label with commonly understood labels } \\
\text { such as "Metered Dose Inhalers" instead of confusing } \\
\text { prescription medication names. } \\
\text { Design solution: Change video category labels from } \\
\text { descriptive to action words (e.g., "Smoking Cessation" } \\
\text { to "Quit Smoking"; "Stress Management" to "Managing } \\
\text { Stress"; "Lifestyle" becomes "Living a Better Life." }\end{array}$ \\
\hline & $\begin{array}{l}\text { \#10: Implement the } \\
\text { shallowest possible } \\
\text { information hierarchy } \\
\text { (minor) }\end{array}$ & $\begin{array}{l}\text { - Available links were not cross-referenced. } \\
\text { - Overlap in some video categories (e.g., lifestyle, exercise, } \\
\text { moving effectively, and physical activity) could limit } \\
\text { search success. }\end{array}$ & $\begin{array}{l}\text { Design solution: Increase font size of subheadings for } \\
\text { the "At-Home Exercise Workout" video page to help } \\
\text { better subdivide the page. }\end{array}$ \\
\hline $\begin{array}{l}\text { Presentation } \\
\text { design }\end{array}$ & $\begin{array}{l}\text { \#18: Use the users' lan- } \\
\text { guage; minimize jargon and } \\
\text { technical terms (major) }\end{array}$ & $\begin{array}{l}\text { - Opening video on pathophysiology of COPD } \\
\text { unnecessarily complex }\end{array}$ & $\begin{array}{l}\text { Design solution: Removed video under the Welcome } \\
\text { tab and replaced with custom-made welcome video } \\
\text { describing how to navigate the site and use the } \\
\text { social media features. }\end{array}$ \\
\hline
\end{tabular}

COPD, chronic obstructive pulmonary disease.

solutions within the COPDFlix prototype. Of the 61 violations identified, 52 (85.2\%) were addressed during the Web modification process. Table 2 lists expert comments used to inform 26 separate design modifications. Table 3 provides examples of identified violations along with descriptions of associated design solutions. One important limitation was lack of data from actual COPD patients. Think-aloud usability testing with COPD patients will follow the heuristic evalu- ation to provide complementary data that will inform more patientcentered improvements to COPDFlix.

\section{Acknowledgments}

This work was supported by the National Institutes of Health (NCATS) under CTSA awards UL1TR000064 and KL2TR000065 to the University of Florida. 


\section{STELLEFSON ET AL.}

\section{Disclosure Statement}

No competing financial interests exist.

\section{REFERENCES}

1. Langsetmo L, Platt R, Pierre $E_{1}$ Bourbeau J. Underreporting exacerbation of chronic obstructive pulmonary disease in a longitudinal cohort. Am J Respir Crit Care Med 2008;177:396-401.

2. National Heart, Lung, and Blood Institute. Take the first step to breathing better: Learn more about COPD. Available at www.nhlbi.nih.gov/health/public/ lung/copd/ (last accessed August 3, 2013).

3. National Center for Health Statistics. FastStats: Chronic obstructive pulmonary disease. May 30, 2013. Available at www.cdc.gov/nchs/fastats/copd.htm (last accessed September 3, 2013).

4. World Health Organization. Chronic obstructive pulmonary disease (COPD). Available at www.who.int/respiratory/copd/en/ (last accessed January 11, 2014).

5. Ferrell K. COPD: When you learn more, you'll breathe better. NIH MedlinePlus $2007 ; 2: 24-25$

6. Hill K, Mangovski-Alzamora S, Blouin M, Guyatt G, Heels-Ansdell D, Bragaglia $P$, et al. Disease-specific education in the primary care setting increases the knowledge of people with chronic obstructive pulmonary disease: A randomized controlled trial. Patient Educ Couns 2010; 81:14-18.

7. Stellefson $M$, Chaney $B$, Chaney JD. Using exploratory focus groups to inform the development of targeted COPD self-management education DVDs for rural patients. Int J Telemed App/ 2010;2010:450418.

8. Effing T, Bourbeau J, Vercoulen J, Apeter A, Coultas D, Meek P, et al. Selfmanagement programmes for COPD moving forward. Chron Respir Dis 2012;9:27-35

9. Hung W, Wisnivesky J, Siu A, Ross J. Cognitive decline among patients with chronic obstructive pulmonary disease. Am J Respir Crit Care Med 2009;180:134-137.

10. Johnson C, Turley J. Approach to building web-based interfaces for healthcare consumers. Electron J Health Inform 2007;2:e2.
11. Stellefson M, Chaney B, Walsh-Childers K, Sriram PS, Chaney D. COPDFlix: A social media resource center for patient-centered self-management training. Clin Trans/ Sci 2013;6:121-122.

12. Petty T. The history of COPD. Int J Chron Obstruct Pulmon Dis 2006;1:3-14.

13. Stellefson M, Chaney B, Chaney D. Examining the efficacy of DVD technology compared to print-based material in COPD self-management education of rural patients. Calif J Health Promot 2009;7:26-42.

14. Nielsen J, Mack RL, editors. Usability inspection methods. New York: John Wiley \& Sons, Inc., 1994.

15. Jaspers MW. A comparison of usability methods for testing interactive health technologies: Methodological aspects and empirical evidence. In J Med Inform 2008;78:340-353.

16. Nielsen J. Usability engineering. Boston: Academic Press, 1993.

17. Chisnell D, Redish JD. Designing Web sites for older adults: A review of recent, relevant research. Washington, DC: AARP Services, Inc., 2004.

18. Chisnell DE, Redish JC, Lee A. New heuristics for understanding older adults as web users. Techn Commun 2006;53:39-59.

19. Choi J, Bakken S. Web-based education for low-literate parents in neonatal intensive care unit: Development of a website and heuristic evaluation and usability testing. Int J Med Inform 2010;79:565-575.

20. Glaser BG, Strauss AL. The discovery of grounded theory: Strategies for qualitative research. Chicago: Aldine, 1967.

Address correspondence to: Michael Stellefson, PhD

Department of Health Education and Behavior University of Florida P.O. Box 118210 Gainesville, FL 32611

E-mail: mstellefson@ufl.edu

Received: January 15, 2014 Accepted: January 27, 2014 